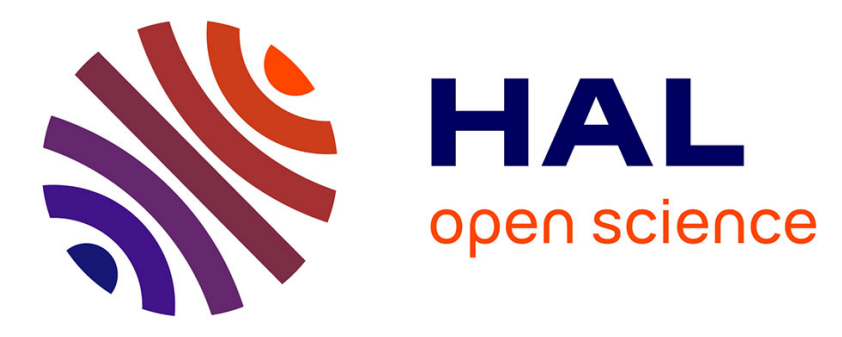

\title{
Cellulose Nanocrystals in Spherical Titania-Sol Microdroplet: From Dynamic Self-Assembly to Nanostructured TiO x /C Microsphere Synthesis
} Cong Wang, Erwan Paineau, Hynd Remita, Mohamed Nawfal Ghazzal

\section{To cite this version:}

Cong Wang, Erwan Paineau, Hynd Remita, Mohamed Nawfal Ghazzal. Cellulose Nanocrystals in Spherical Titania-Sol Microdroplet: From Dynamic Self-Assembly to Nanostructured $\mathrm{TiO} \times$ /C Microsphere Synthesis. Chemistry of Materials, 2021, 33 (17), pp.6925-6933. 10.1021/acs.chemmater.1c01865 . hal-03367479

\author{
HAL Id: hal-03367479 \\ https://hal.science/hal-03367479
}

Submitted on 6 Oct 2021

HAL is a multi-disciplinary open access archive for the deposit and dissemination of scientific research documents, whether they are published or not. The documents may come from teaching and research institutions in France or abroad, or from public or private research centers.
L'archive ouverte pluridisciplinaire HAL, est destinée au dépôt et à la diffusion de documents scientifiques de niveau recherche, publiés ou non, émanant des établissements d'enseignement et de recherche français ou étrangers, des laboratoires publics ou privés. 


\title{
Cellulose Nanocrystals in Spherical Titania-Sol Microdroplet: From Dynamic Self-Assembly to Nanostructured $\mathrm{TiO}_{\mathbf{x}} / \mathrm{C}$ Microsphere Synthesis
}

\author{
Cong Wang, ${ }^{[a]}$ Erwan Paineau, ${ }^{[b]}$ Hynd Remita, ${ }^{[a]}$ Mohamed Nawfal Ghazzal ${ }^{*[a]}$
}

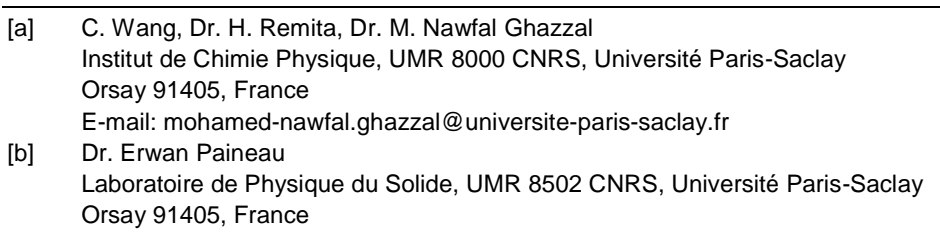

\begin{abstract}
The study and control of cellulose nanocrystals (CNCs) self-assembly in spherical confinement remains a challenging and unexplored area. It is difficult to directly observe the self-organization of CNCs in such geometry. Herein, a dynamic observation of the selforganization process of CNCs in confined titania-sol microdroplet is reported. The isotropic to cholesteric transition undergoes nucleation, coalescence and migration of tactoids through two coalescence mechanisms, namely "head-to-tail" and "side-to-side" types. The solubility and self-organization of CNCs in titania-sol enable a successful transfer of the chiral $(\mathrm{Ch})$ nematic structure into hybrid $\mathrm{TiO}_{x} / \mathrm{C}$ microspheres. $\mathrm{TiO}_{x} / \mathrm{C}$ microspheres show higher photocatalytic $\mathrm{H}_{2}$ generation compared to $\mathrm{TiO}_{2}-\mathrm{P} 25$. This work adds to the understanding of self-assembly process of CNCs in spherical geometry, and provides a fresh avenue to design nanostructured photoactive microspheres with unique $\mathrm{Ch}$ nematic structures.
\end{abstract}

Keywords: cellulose nanocrystals • tactoids $•$ self-organization • spherical confinement

\section{INTRODUCTION}

Cellulose nanocrystals (CNCs) are spindle-like rods derived from a variety of natural resources via strong acid hydrolysis, ${ }^{1}$ which can spontaneously organize into a cholesteric structure, called chiral (Ch) nematic structure..$^{2-4}$ The self-organization of CNCs into well-ordered $\mathrm{Ch}$ nematic liquid crystals are ubiquitous in nature, ${ }^{5}$ inspiring widespread interest in the development of green functional materials with versatile applications, such as biomimetic nanomaterials, soft nanotechnology, optoelectronics and photocatalysis technology. ${ }^{6-9}$

The transfer of such natural Ch nematic nanostructures into artificial spherical functional materials on the nano- or micro-scale, however, is challenging. ${ }^{10}$ Typically, studies have focused on obtaining long-range ordered $\mathrm{Ch}$ nematic structure in planar functional films by using evaporation-induced self-assembly (EISA) method. ${ }^{11-14}$ To obtain this Ch nematic structure in a small film area, i.e. microfilms, EISA is not applicable and the use of a sophisticated printing method is required. ${ }^{15}$ Evaporation is essential to achieve equilibrium during isotropic-to-anisotropic transition. The phase transition starts with the nucleation of helical twist in localized spaces, which are called tactoids. As a key component for fundamentally understanding of the self-assembly process of Ch nematic structure, tactoids can dynamically bridge the disordered isotropic phase and the ordered $\mathrm{Ch}$ nematic phase. ${ }^{16}$ The importance of tactoids in constructing functional material by controlling the liquid crystal properties has been highlighted, since Lagerwall and coworkers showed that the optical properties of the photonic films could be improved by applying shear forces to suspensions of CNCs during drying. ${ }^{17}$ The shear forces improved the alignment of the tactoids, and consequently ameliorated the quality of the films. In planar geometries, water evaporation of the CNCs suspension will initiate the coalescence and sedimentation of tactoids, and eventually compress them into long-range lamellar liquid crystalline phase. ${ }^{18}$ Significantly, such planar organization mechanism is not applicable to three-dimensional constrained geometry, especially to target materials with spherical morphology that exceed the restriction of film shape.

Spherical confinement of $\mathrm{Ch}$ nematic liquid crystals are of particular interest in potential applications of sensing, actuators or lasers, optical devices and chiral molecular switches, due to their triggered novel topological structures and special geometries. ${ }^{19-24}$ However, only a few attempts have been dedicated to investigate the Ch nematic structure of CNCs aqueous suspension in confined microdroplets. ${ }^{25-29}$ Although these studies have macroscopically described the evolution of CNCs under spherical constraint as a simple isotropic-to-anisotropic phase transition, the exhaustive organization process remains largely unexplored, in particular with regard to the involvement of inorganic precursors. Moreover, the stability of precursors (metal chlorides or alkoxides) is highly sensitive to moisture, leading to a fast condensation which destabilizes the Ch nematic structure into the isotropic phase. ${ }^{7}$ Thus, further investigations aimed at providing additional insights in the organization process of CNCs in water or in the presence of precursors are meaningful and necessary.

In this study, we encapsulated CNCs in spherical titania-sol microdroplets using an inverse microemulsion method. We monitored the self-assembly process from seconds to hours with the aim to determine the key steps that drive the self-organization of CNCs from isotropic to Ch nematic phase in such aqueous sol. Polarized optical microscopy (POM) provides a unique perspective to witness the evolution process of CNCs tactoids from nucleation, growth and migration to equilibration in spherical microdroplet. Simultaneously, growth mechanisms as well as the induced structural defects during different evolution stages have been identified during the process. Moreover, the impact of temperature on the Ch nematic structure was investigated and a proof-of-concept of the transfer of such structure into solid $\mathrm{TiO}_{x} / \mathrm{C}$ microspheres by hydrothermal method was demonstrated. The hybrid $\mathrm{TiO}_{x} / \mathrm{C}$ microspheres exhibited high absorption in the visible range and promising application in photocatalytic $\mathrm{H}_{2}$ generation. This study therefore provides insights into the selfassembly process of CNCs in spherical confinement, favouring 
further comprehension of growth mechanism as well as opening up a new approach to transfer the Ch nematic structure into spherical nanostructured materials. Furthermore, it is also relevant for a wide range of disciplines (such as Mie scattering, catalysis) to synthesize advanced hybrid materials with rodshaped particles or liquid crystals.

\section{RESULTS AND DISCUSSION}

\subsection{Optimization of CNCs concentration.}

To understand the role of spherical confinement, it is necessary to investigate first the influence of initial CNCs concentration before encapsulation. The main objective is the optimization of CNCs content in titania-sol, ensuring the spontaneous phase transition from isotropic to $\mathrm{Ch}$ nematic. This phase transition depends on the concentration of CNCs, but also on the $\mathrm{pH}$, ionic salt and residual sulfur ratio. ${ }^{30-32}$ Considering these facts, variable concentrations of CNCs suspension blended with different volumes of $\mathrm{Ti}(\mathrm{acac})_{2}(\mathrm{OiPr})_{2}(\mathrm{TAA})$ precursor under constant $\mathrm{pH}$ $(\sim 6)$ were prepared (Figure 1c, Figure S1 and Table S1), where acetylacetonate is used as a chelating agent to inhibit fast condensation of the precursor. ${ }^{7}$ The CNCs suspensions exhibited birefringence under polarized light (Figure 1a). Typical fingerprintlike structures with alternated bright and dark lines can also be observed under POM, which indicated the formation of Ch nematic phases (Figure 1b, Figure S2). ${ }^{3}$ The addition of TAA precursor led to the dilution of CNCs suspensions, resulting in the reversion from $\mathrm{Ch}$ nematic to isotropic phases (shown black domain under POM) (Figure 1d). ${ }^{33-35}$ The birefringence and fingerprint patterns reappeared when the CNCs concentration further increased. The distances between bright and dark lines correspond to half of the helical pitch $(P$, defined as the distance for a $360^{\circ}$ rotation of $\mathrm{CNCs}$ rod), which is the key characteristic of Ch nematic phase. ${ }^{36,37}$ The value of $P$ tightened from 6.2 to 3.2 $\mu \mathrm{m}$ as the concentration increased from 4 to $6 \mathrm{wt} \%$, which has been attributed to the close packing of the CNCs rods, thus resulting in stronger intermolecular interactions as well as more pronounced birefringence (Figure 1a and 1e, Table S2). ${ }^{38,} 39$ In this concentration range, the magnitude of the $P$ should scale with the inverse of the aspect ratio, $P \propto \mathrm{D} / \mathrm{L}$, which is usually observed for colloidal solution. ${ }^{37,} 40$ In our case, the $P$ is inversely proportional to concentration, $P \propto \mathrm{C}^{-1}$, and the fraction of the anisotropic phase to the isotropic phase, as expected from Straley modelling of chiral nonflexible rods. ${ }^{41}$ Moreover, two main mechanisms could be involved in rationalizing the decrease in $P$ as the CNCs concentration increased. ${ }^{42}$ The first one is related to the helix formation. Basically, the chirality transfer in liquid crystals is driven by the transfer of the chirality of the molecular cellulose to the macroscopic ordering of the liquid crystal phase. The larger the amount of CNCs in the solution, the stronger the total cohesion of the twist. ${ }^{43}$ The second one is driven by the increase of the ionic strength (due to the negatively charged CNCs rods) upon increasing the CNC concentration. This leads to an exponential decay of the electrostatic repulsion and thus allows CNCs rods closer to each other. Notably, the value of $P$ tended to level off at high concentrations (> $6 \mathrm{wt} \%$ ), accompanied by obvious birefringence (Figure 1f). ${ }^{44}$
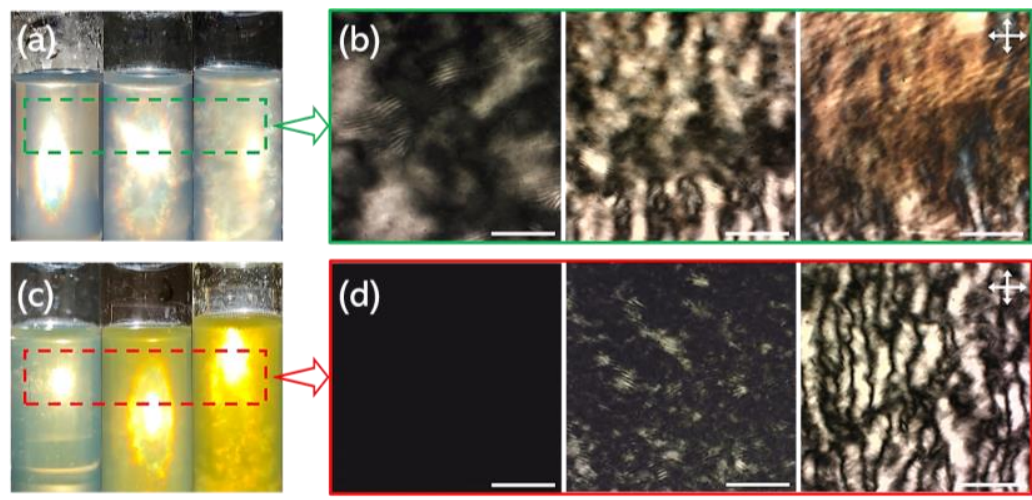

(f)

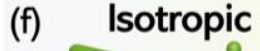

Chiral Nematic
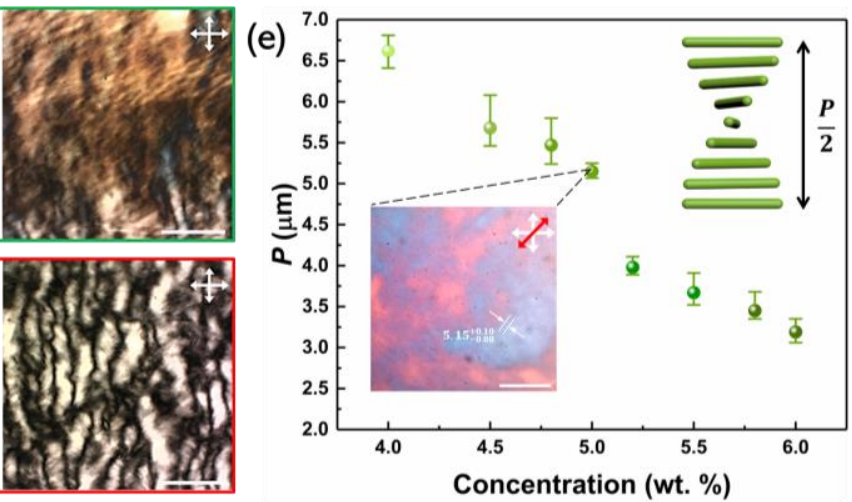

Concentration (wt. \%)

Birefringence

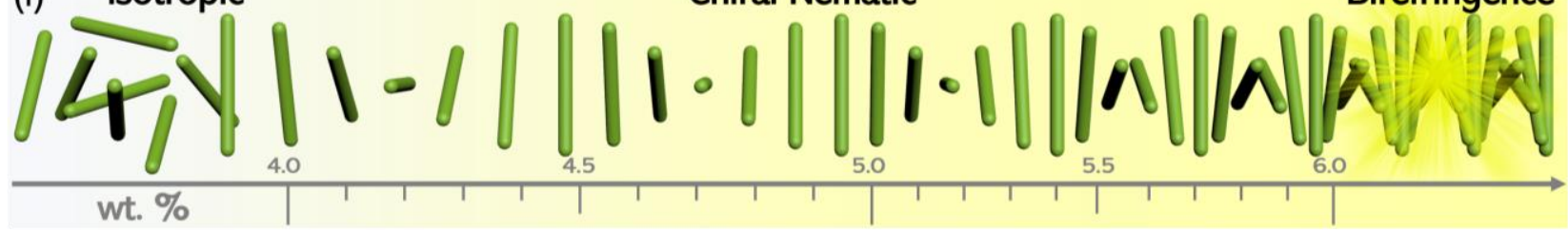

Figure 1. (a) Photographs under polarized light and (b) typical POM images of $\mathrm{CNC}$ suspensions (from left to right, $\mathrm{CNC}_{4 \%}$, $\mathrm{CNC}_{6 \%}$, and $\mathrm{CNC}_{8 \%}$ ). (c) $\mathrm{Photographs}$ under polarized light and (d) POM images of TAA/CNC mixtures (from left to right, TAA/CNC $4 \%$, TAA/CNC $\%$, and TAA/CNC $8 \%$ ). (e) Variation of the helical pitch value with the CNCs mass fraction. The insets include a schematic representation of half pitch $(P / 2)$ and a representative $P O M$ image of $C C_{5 \%}$ (showing a $P$ value of $5.15 \mu \mathrm{m})$ recorded with a retardation $\lambda$-plate $(530 \mathrm{~nm}$ ). (f) Schematics of Ch nematic structure (from isotropic phase to Ch nematic phase and obvious birefringence). All scale bars correspond to $50 \mu \mathrm{m}$.

\subsection{Production of TAA/CNC microdroplets.}

With these results, inverse microemulsion method was employed to encapsulate CNCs and TAA/CNC microdroplets with diameter
(Ф) of $110 \sim 170 \mu \mathrm{m}$ (Figure 2a, Table S3). Compared with microfluidic, the size distribution of micodroplets through microemulsion method is less well controlled. However, this 
simple method enables the rapid emulsification of microdroplets and is easy to implement, offering the opportunity to capture and investigate the primitive states of tactoids by using POM. The use of water-in-oil microemulsion avoids the evaporation of water from the microdroplets, allowing the self-organization in confined microspheres to be studied over time scales from seconds to hours. In standard procedure, $3 \mathrm{~mL}$ of the sonicated CNCs suspensions or TAA/CNC mixtures were added dropwise into cyclohexane ( $30 \mathrm{~mL}$, containing 2 wt\% Span 80 ) under constant stirring speed $(500 \mathrm{rpm})$ to obtain relatively uniform microdroplets. Fresh microdroplets were collected into an unsealed capillary after $1 \mathrm{~min}$ emulsification at ambient temperature $\left(20^{\circ} \mathrm{C}\right)$, allowing the primitive state to be studied under POM. The concentration of CNCs suspensions varied from 4 to $8 \mathrm{wt} \%$, in order to assess the threshold at which the isotropic-to-anisotropic phase transition occurred in microdroplets. The optical characteristics of CNCs in microdroplets are similar to that observed in homogeneous suspensions (Figure 2b-g, Figure S3 and Table S3). However, for newly collected microdroplets, especially at low CNCs ratio, the isotropic phase was predominant.

CNCs rods start to self-organize in birefringent tactoids that nucleate and grow over time (Figure $2 \mathrm{~b}$ and $2 \mathrm{f}$ ). Onsager, in his pioneering work, ${ }^{45}$ predicted that homogeneous dispersions of rod particles with high aspect ratios may undergo a phase separation spontaneously. This is due to a competition between orientational entropy and free volume entropy due to excludedvolume interactions. Intuitive observation of POM showed that the dark areas were gradually replaced by bright bands, indicating the onset of isotropic to Ch nematic phase transition (nucleation of tactoids) (Video S1). At this primitive nonequilibrium state, the value of $P$ in tactoids is generally higher than that in suspensions (Table S1 and S3). In addition, the $P$ value for TAA/CNC microdroplets is further expanded compared to CNCs microdroplets, owing to the insertion of the TAA precursor. Tactoid formation progressed weakly (may last several hours) under a low concentration of CNCs. The low local density reduces the probability of interactions between the CNCs rods, which slows down their interactions and phase transition kinetics. Comparatively, nucleation and coalescence can proceed simultaneously at higher concentrations (Figure $2 f$ and $2 h$ ). Based on these findings, we focus on following the case of $\mathrm{TAA} / \mathrm{CNC}_{6} \%$ microdroplet to ensure the acquisition of detailed information on the nucleation and coalescence mechanism of tactoids in confined titania-sol microdroplet for a short period. (a)

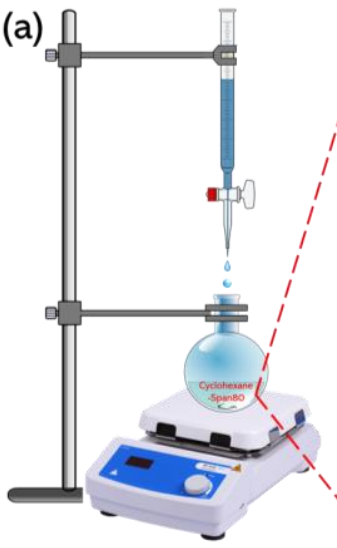

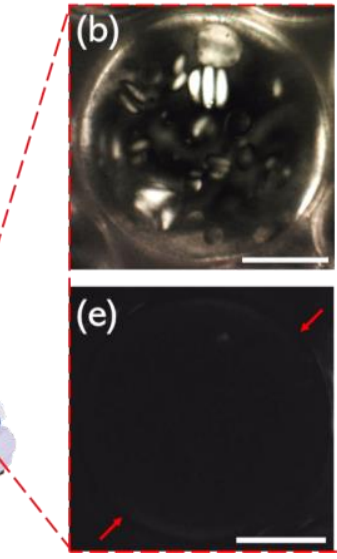
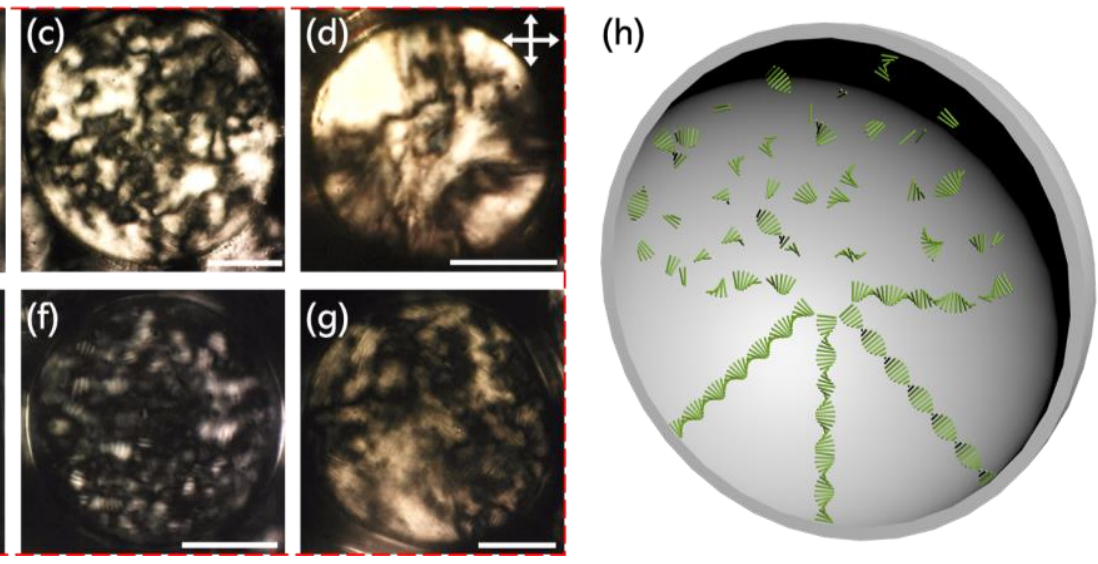

Figure 2. (a) Cartoon illustration of inverse microemulsion system. POM images of microdroplets of (b) $\mathrm{CNC}_{4 \%}$, (c) $\mathrm{CNC}_{6} \%$, (d) $\mathrm{CNC}_{8 \%}$, (e) $\mathrm{TAA} \mathrm{CNC}_{4 \%}$, (f) $\mathrm{TAA} / \mathrm{CNC}_{6} \%$ and $(\mathrm{g}) \mathrm{TAA} / \mathrm{CNC}_{8 \%}$ (scale bars $\left.=50 \mu \mathrm{m}\right)$. (h) Schematic of microdroplet.

\subsection{Revealing the evolution process.}

To further investigate the evolution process from isotropic to $\mathrm{Ch}$ nematic phase and reveal the growth mechanism of tactoids in spherical confinement, the internal structure progress of one TAA $/ \mathrm{CNC}_{6 \%}$ microdroplet $(\Phi \sim 110 \mu \mathrm{m})$ was tracked under POM after $\sim 30$ seconds of rapid-term emulsification at $20^{\circ} \mathrm{C}$ (Figure 3 , Video S2). The use of a lambda retardation plate allowed us to determine the preferred orientation of CNCs directors in the $\mathrm{Ch}$ nematic phase within the microdroplet (Figure 3 b1-b8). At the beginning, isotropic phases dominated the microdroplet, in which small tactoids started to nucleate with one or two periodic bands (Figure 3 a1-c1). After 60 seconds of evolution, newborn tactoids grew into larger ones with more bands through coalescence (Figure 3 a2-c2). Note that the orientations of the directors of each tactoid were well aligned, but they were randomly oriented with respect to each other (Figure 3 b2 and c2). Two different types of coalescence mechanisms were evidenced, which will be further discussed later. These newborn tactoids had spherical or ellipsoidal shapes, attributing to the interfacial tension between isotropic and anisotropic phases. ${ }^{46}$ After several minutes of growth, CNCs tactoids progressively migrated to the periphery of the microdroplet (water/oil interface), driving by the phase separation induced by both the spherical confinement and Marangoni flows (Figure 3 a3-c3). ${ }^{27}, 47$ The fusion and rearrangement of adjacent tactoids were driven by the water/oil interface tensions (Figure 3 a4-c4), generating large distinct $\mathrm{Ch}$ nematic domains. Interestingly, the periodic stripe patterns also bent to accommodate the spherical boundary of microdroplet (Figure 3 a5-c5). As the process progressed, the ends of flexural bands continue to extend along with the interface until they bordered contiguous domains, triggering the onset of domain integration. Due to larger volume than tactoids, the integration process between domains tended to require a longer time, which is usually accompanied by the onset of topological defects (Figure 3 a6-c6). The vanishing of defects indicated the completion of the integration process. Spherical packing of CNCs started at the water/oil interface with the assistance of the tangential surface anchoring, and maintained the propagation toward the 
microdroplet centre (Figure 3 a7-c7). Newly formed spherical structures were asymmetric owing to stochastic nature in the fusion process. After approximately two hours of equilibration time CNCs in the microdroplet exhibited uniform radial alignment (Figure 3 b8). Meanwhile, alternating bright and dark concentric rings were superimposed with a Maltese cross pattern (hedgehog point defect) that corresponded to the characteristic features of the Ch nematic phase (Figure 3 a8-c8).

\subsection{Mechanism discussion.}

Distinct Maltese cross originated from the radial alignment between isoclines of the $\mathrm{Ch}$ nematic helix axis with respect to the polarizers. ${ }^{26}$ Obviously, incomplete phase separation may leave an anisotropic core, exhibiting a variable pseudo-Maltese cross patterns. Since the anisotropic core equipped with a specific orientation, the central area of the pseudo-Maltese cross will alternately brighten and darken when the microdroplet remained mobile or change its orientation with respect to the polarizer (Video S3). We noticed that the central region showed parallel stripes with variable widths during the brightening process (Figure S4). There were two defects at the ends of the core, which splitted one $S=+1$ topological charge into two $S=+1 / 2$ charges, likely contributing to minimizing the free energy of the highly frustrated liquid crystalline. ${ }^{48-50}$ This ubiquitous phenomenon existed during the phase separation, while smaller microdroplets (further confinement) often biased towards the appearance of bipolar stripe pattern (Figure S5). ${ }^{28}$ Maltese cross pattern with a birefringent feature covered the core of the microdroplet, which changed as the width of the lamellar core increases (Figure S4), evidencing the roles of defects. After adequate phase separation and a sufficient equilibrium period, the microdroplet will form a core-shell structure, that is, a Ch nematic shell with concentrically packed CNCs pseudo-layers and an isotropic core (Figure 3 a8, Figure S6), where the size of core is dependent on the volume fraction of CNCs. ${ }^{28,}{ }^{29}$ Remarkably, the equilibrium state of the microdroplet has to be accompanied by a specific number of defects, such as the dislocation of spherical pseudo-layers at the microdroplet periphery (Figure S $7 \mathrm{a}$ ). ${ }^{27}$ Such dislocation stemmed from the inconsistent relaxation progress of CNCs, leading to a local coincidence between adjacent bright spherical pseudolayers (Figure S 7b). ${ }^{51}$

\section{Time Evolution}
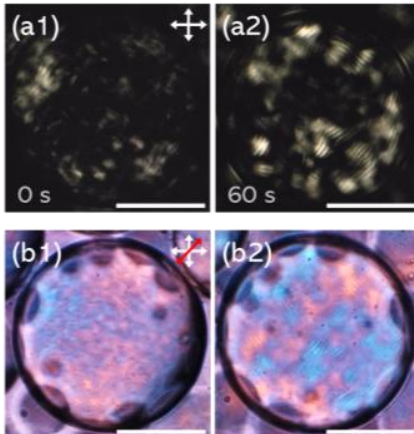

(c1)

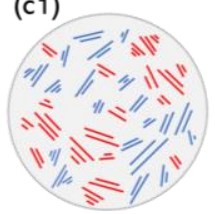

(c2)
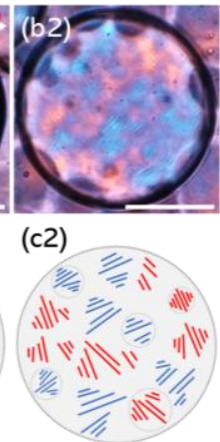

(c3)
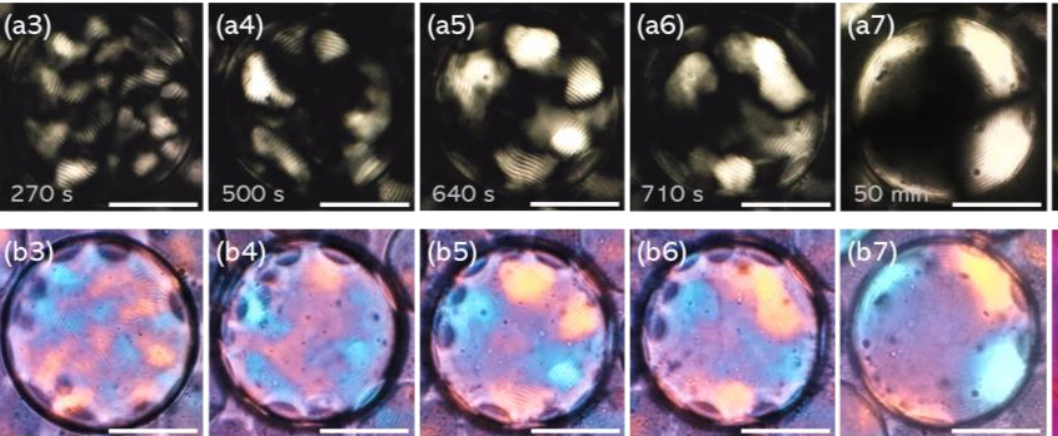

(c4)
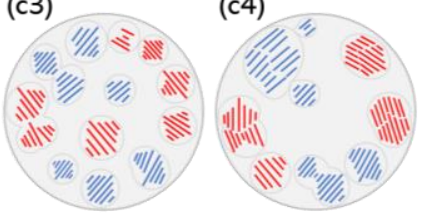

(c5)

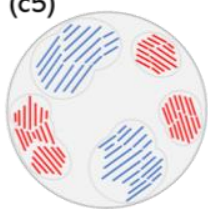

(c6)
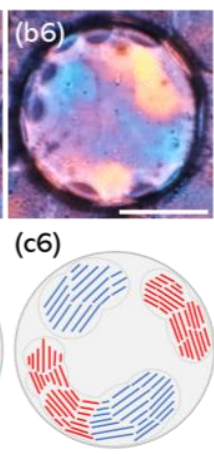

(c7)
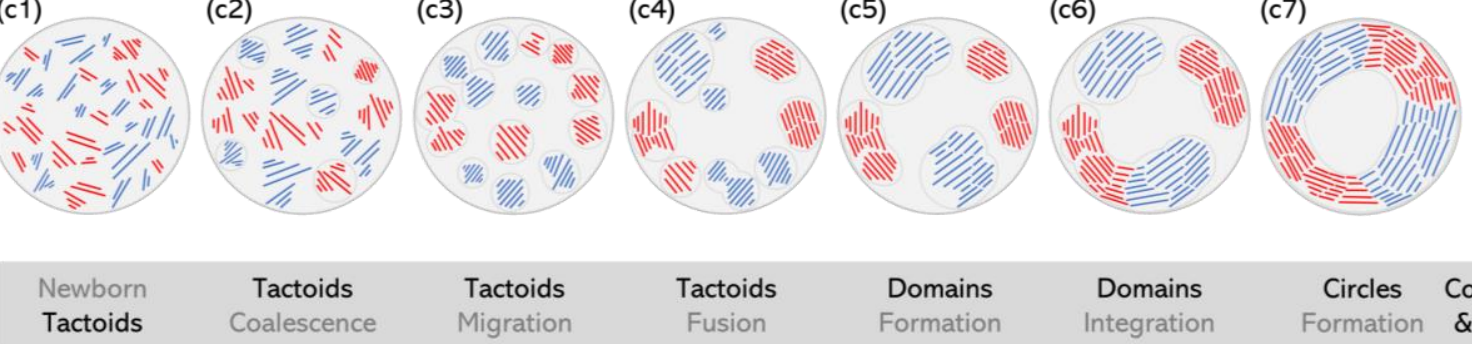

Tactoids
Coalescence
Tactoids Migration

\begin{abstract}
Tactoids Fusion
\end{abstract}

\begin{abstract}
Domains
\end{abstract} Formation

Domains
Integration

(c8)
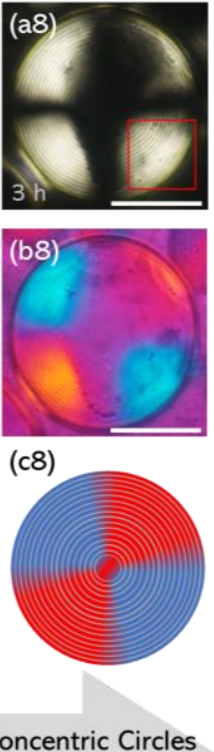

Circles Concentric Circles Formation \& Maltese Cross

Figure 3. Typical POM images of time-series snapshots of $\mathrm{TAA} / \mathrm{CNC}_{6} \%$ microdroplet without (a1-a8) and under lambda retardation plate (b1-b8) (scale bar = 50 $\mu \mathrm{m})$. Note that (a8) and (b8) was captured by using high magnification camera once equilibrium was reached. (c1-c8) Corresponding cartoon depiction of the microdroplet transforms from newborn tactoids to symmetrical concentric circles with Maltese cross structure.

The point of marked difference between planar and spherical geometries lies in the driving mechanism. Evaporation and sedimentation play the main roles in planar geometry, whereas in confined microdroplet, the coalescence process is driven by the phase separation induced by spherical confinement and the Marangoni flow. The conformation of tactoids stems from nucleation and rearrangement of mobile CNCs rods, while growth depends mainly on coalescence. In our observations, two different types of coalescence mechanism were depicted, namely "head-to-tail" and "side-to-side" types. The "head-to-tail" concerned two ellipsoidal-like tactoids $(\sim 10 \mu \mathrm{m})$ with quite linear helical directors. The tactoids rotated until their helical directors perfectly matched via electrostatic attraction, resulting in a larger tactoid with multiplied periodic bands (Figure 4a, Figure S8, Video S4 and S5). For "side-to-side" coalescence, the helical directors of two tactoids were parallel to each other, and then tilted to form a $25^{\circ}$ angle by the attraction between the CNCs rods, allowing the insertion of the bands and eventually forming a larger tactoid with long periodic bands (Figure 4b, Figure S9, Video S4 and S5). This coalescence type usually produced $\mathrm{Y}$-shaped defects, and lasted 
longer than "head-to-tail" type due to the involvement of bands fusion and rearrangement. In addition, another form was sometimes observed, that is, aligned "side-to-side" coalescence (Figure S10), which tended to occur between tactoids with similar volume and the same number of bands. We do not rule out the possibility of another coalescence mechanism, such as the "headto-side" type observed during the formation of planar films. ${ }^{18}$ This case commonly requires high kinetics energy (e.g. during evaporation or heating) to fold the periodic bands of one tactoid and merge into another tactoid. Coalescence processes are accompanied by the appearance of defects, while they are not easy to be captured due to the small number of tactoids in early growth state and relatively short coalescence time. (a)

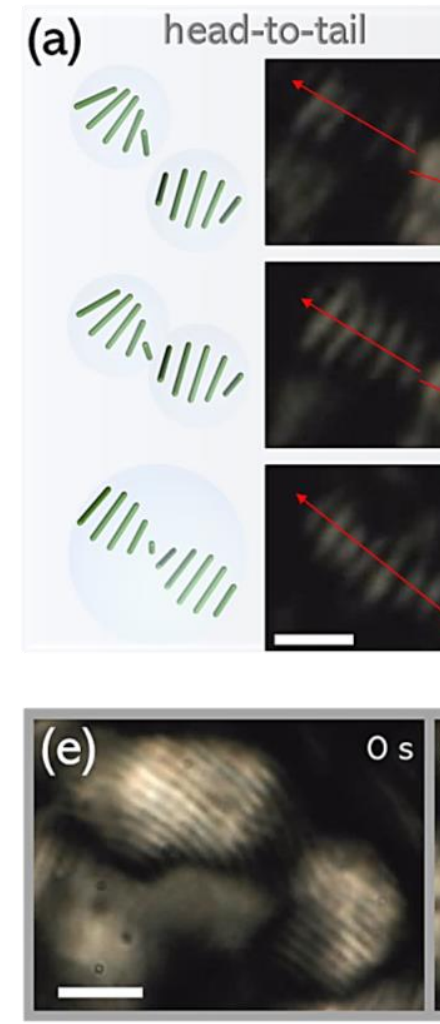

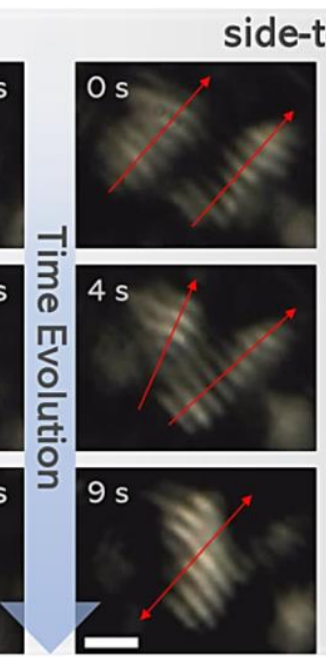

side-to-side

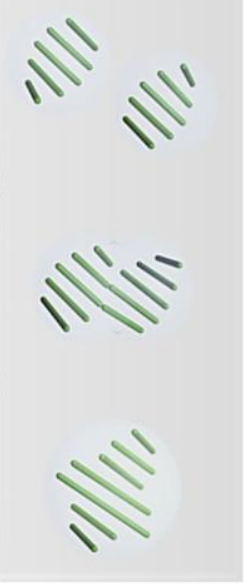

(b)

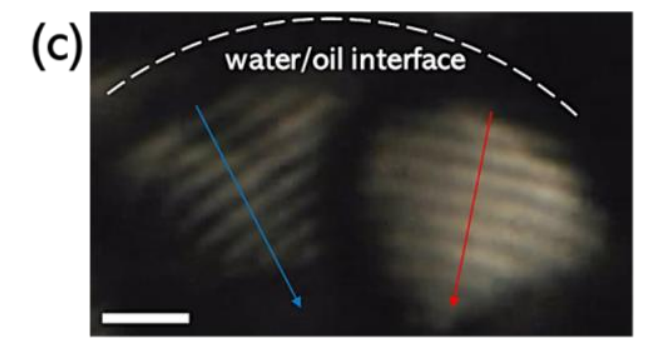

(d)

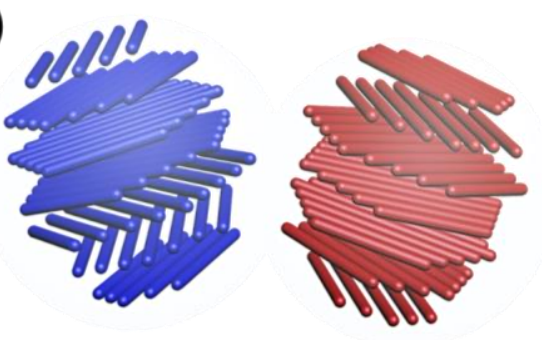

(h)

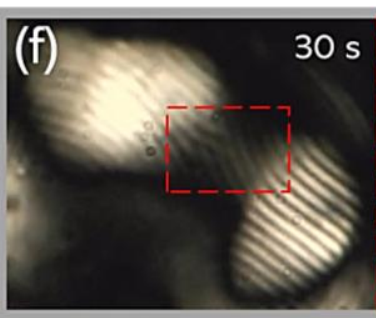

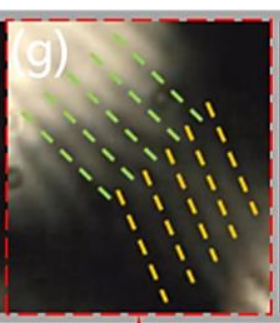
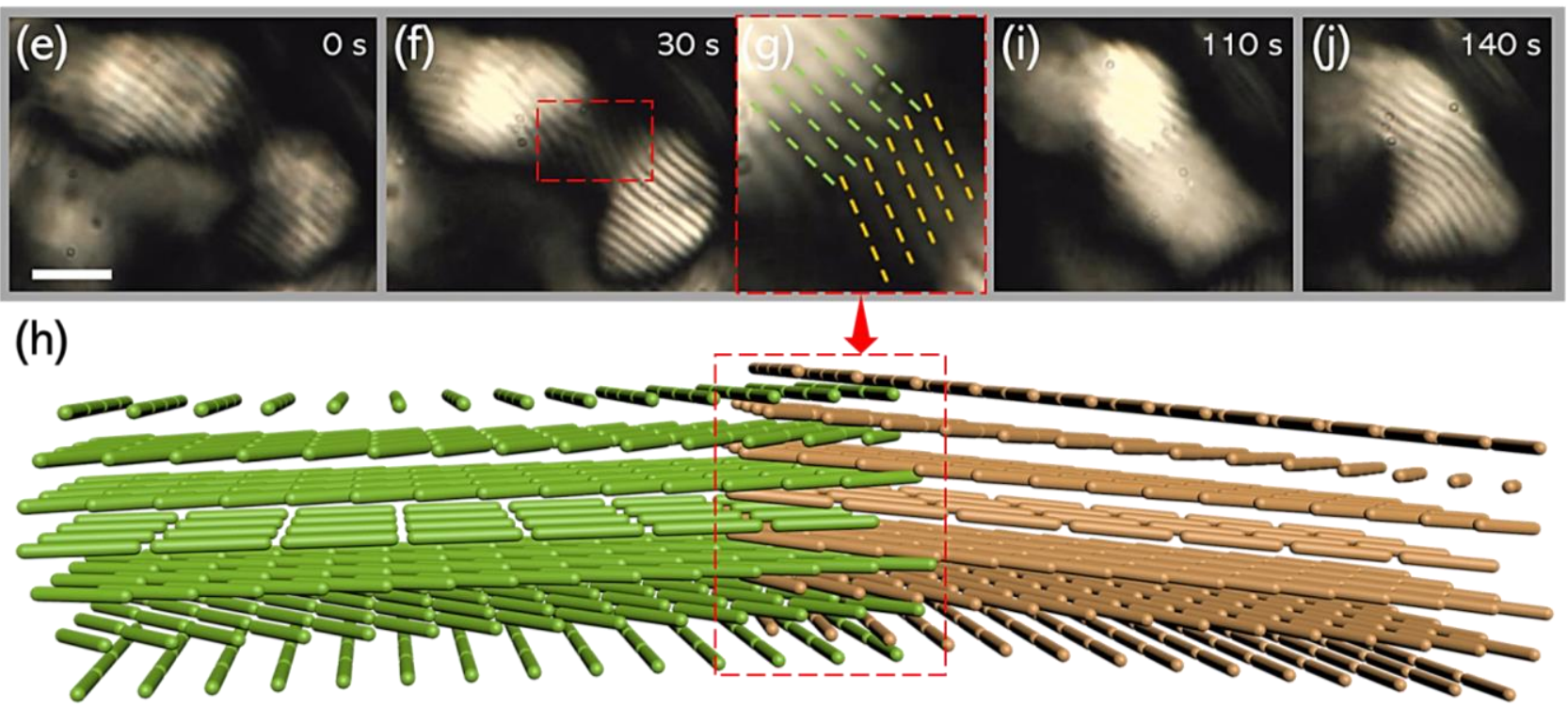

Figure 4. POM images and corresponding 3D models showing two different types of coalescence mechanism of tactoids: (a) head-to-tail and (b) side-to-side (scale bar $=10 \mu \mathrm{m}$ ). (c) POM image of tactoids anchored on the water/oil interface with their helical axes to the centre of microdroplet (scale bar $=10 \mu \mathrm{m})$. (d) Corresponding $3 \mathrm{D}$ models of anchored tactoids. (e-j) POM images revealing the dislocation and fusion occurring during the domain integration $($ scale bar $=20 \mathrm{~mm}$ ). ( $\mathrm{h}$ ) Corresponding 3D models of dislocation and fusion.

As evolution progressed, larger tactoids will gradually migrate to the periphery of the microdroplet as a result of phase separation, and will be anchored on the water/oil interface, with their helical axes pointing to the centre as well as local directors consistent with the planar anchor on microdroplet surface (Figure $4 \mathrm{c}$ and $4 \mathrm{~d})$. The orientation of planar anchor was orthogonal to the helical axis and has the capability to impose spherical curvature to the periodic bands. These anchored tactoids or larger
Ch nematic domains preferentially fused through the "side-toside" pathway. Since the initial states of these domains were out of synchronization, dislocation defects were usually formed in the director field (Figure 4e-h). Such defects, however, can be restored through the resynchronization and reorientation of the director axis due to their thermodynamic destabilization. The integration process between the two domains will last for a few minutes depending on the relaxation rate of CNCs, and will 
always be accompanied by obvious birefringence (Figure 4i and 4j). Spherical pseudo-layers could be observed after the periphery of the microdroplet was completely packed by the CNCs domains (Figure 3 a7).

2.5. Transfer of $\mathrm{Ch}$ nematic structures to $\mathrm{TiO}_{\mathrm{x}} / \mathrm{C}$ hybrid microspheres.

The concentration of CNCs plays a critical role in its selforganization process under a spherical constraint. Apart from this, an appropriate increase in temperature can promote the shortening of the evolution period. At the same time, higher temperature produced heat stress inside microdroplet, which assisted the phase separation, but also squeezed the $P$ (Figure $5 \mathrm{a}$, Figure S11). To demonstrate the feasibility of transferring such $\mathrm{Ch}$ nematic structures from microdroplets to solid microspheres, the $\mathrm{TAA} / \mathrm{CNC}_{6 \%}$ microdroplets were emulsified at $60{ }^{\circ} \mathrm{C}$ for 90 min to ensure the thoroughly phase separation, and then converted into nanostructured $\mathrm{TiO}_{x} / \mathrm{C}$ microspheres $(\Phi \sim 115$ $\mu \mathrm{m})$ by a hydrothermal reaction $\left(180^{\circ} \mathrm{C}\right.$ for $\left.18 \mathrm{~h}\right)$. Scanning electron microscopy (SEM) was used to reveal the morphology and the structure of solid $\mathrm{TiO}_{x} / \mathrm{C}$ microspheres. The buckling and deformation of the microspheres were caused by the gradient of the pressure between TAA condensation and water extrusion during the condensation process in the hydrothermal reaction. (Figure 5b). ${ }^{26,52}$ Besides, there was a noticeable hole in the centre of the microsphere, pointing out a preferential localization of the TAA during the CNCs self-organization in the spherical microdroplet. The TAA was assembled in the spherical shell instead of the core. More importantly, we observed parallel stripe patterns on the surface of microspheres (Figure S12), suggesting a potential transfer of $\mathrm{Ch}$ nematic structure to $\mathrm{TiO}_{x} / \mathrm{C}$ microspheres. To verify our hypothesis, the microspheres were cracked in liquid nitrogen after being embedded in epoxy resins, enabling the direct observation of the cross section of hybrid microspheres. The SEM images showed Ch nematic structures with periodic lamellar bands, which were captured into the $\mathrm{TiO}_{x} / \mathrm{C}$ microsphere wall (Figure $5 \mathrm{c}-\mathrm{g}$ and Figure S13). This further demonstrated the successful replication of the $\mathrm{Ch}$ nematic structure from $\mathrm{TAA} / \mathrm{CNC}$ microdroplets to hybrid $\mathrm{TiO}_{x} / \mathrm{C}$ microspheres. The thermogravimetric analysis (TGA) was employed for identifying the titania content in $\mathrm{TiO}_{x} / \mathrm{C}$ (Figure S14). The weight loss before $200{ }^{\circ} \mathrm{C}$ was mainly caused by the evaporation of moisture. The sharp weight decrease ranging from 200 to $420^{\circ} \mathrm{C}$ corresponded to the combustion of carbon species, which implied $\sim 23.5 \%$ of $\mathrm{TiO}_{2}$ remained in $\mathrm{TiO}_{x} / \mathrm{C}$ microspheres. Surface analysis by X-ray photoelectron spectroscopy (XPS) enabled to determine the surface compositions of hybrid microspheres. The survey showed the presence of $\mathrm{Ti}, \mathrm{C}$ and $\mathrm{O}$ species (Figure S15). The $\mathrm{Ti} 2 \mathrm{p}$ spectrum exhibited two contributions, $2 p_{3 / 2}$ and $2 p_{1 / 2}$ arose from spin orbit-splitting, located at respectively 459 and $464.7 \mathrm{eV}$, which is consistent with $\mathrm{Ti}^{4+}$ in $\mathrm{TiO}_{2}$ (Figure 5h). ${ }^{53}$ Likewise, the shoulder Ti $2 \mathrm{p}_{1 / 2}$ at 460.2 $\mathrm{eV}$ that corresponding to $\mathrm{Ti}^{3+}$ can be confirmed, ${ }^{54}$ which could be attributed to the reduction of $\mathrm{Ti}^{4+}$ by carbon obtained from the dehydration of CNCs during the hydrothermal reaction. The crystalline form of $\mathrm{TiO}_{x}$ was characterized by wide-angle X-ray scattering (WAXS), showing the broad diffraction patterns corresponding to the nanosized $\mathrm{TiO}_{2}$ crystallites in the anatase form (Figure 5i). Additional diffraction patterns are observed and could be attributed to sub-stoichiometric $\mathrm{TiO}_{\mathrm{x}}$ materials, in agreement with the presence of $\mathrm{Ti}^{3+}$ oxidation state detected in XPS analysis. The UV-visible spectra of $\mathrm{TiO}_{x} / \mathrm{C}$ displayed a redshift absorption in the visible region (Figure S16), attesting to the presence of sub-stoichiometric phase in titanium dioxide. Moreover, this $\mathrm{TiO}_{x} / \mathrm{C}$ microspheres with $\mathrm{Ch}$ nematic shell structures exhibited excellent photocatalytic hydrogen evolution activity $\left(196.7 \mu \mathrm{mol} \mathrm{g}{ }^{-1} \mathrm{~h}^{-1}\right)$ compared to commercial $\mathrm{TiO}_{2}-\mathrm{P} 25$ $\left(134.7 \mu \mathrm{mol} \mathrm{g}^{-1} \mathrm{~h}^{-1}\right.$ ) (Figure 5j, Figure S17). The increase in photocatalytic activity could be attributed to the broad absorption of $\mathrm{TiO}_{x} / \mathrm{C}$ and the light scattering induced by the $\mathrm{Ch}$ nematic structure of hybrid nanostructured microspheres. ${ }^{55}$ These results provide a new perspective to obtain sub-stoichiometric titania oxides with improved light harvesting ability, showing great potential applications in photocatalysis field. 

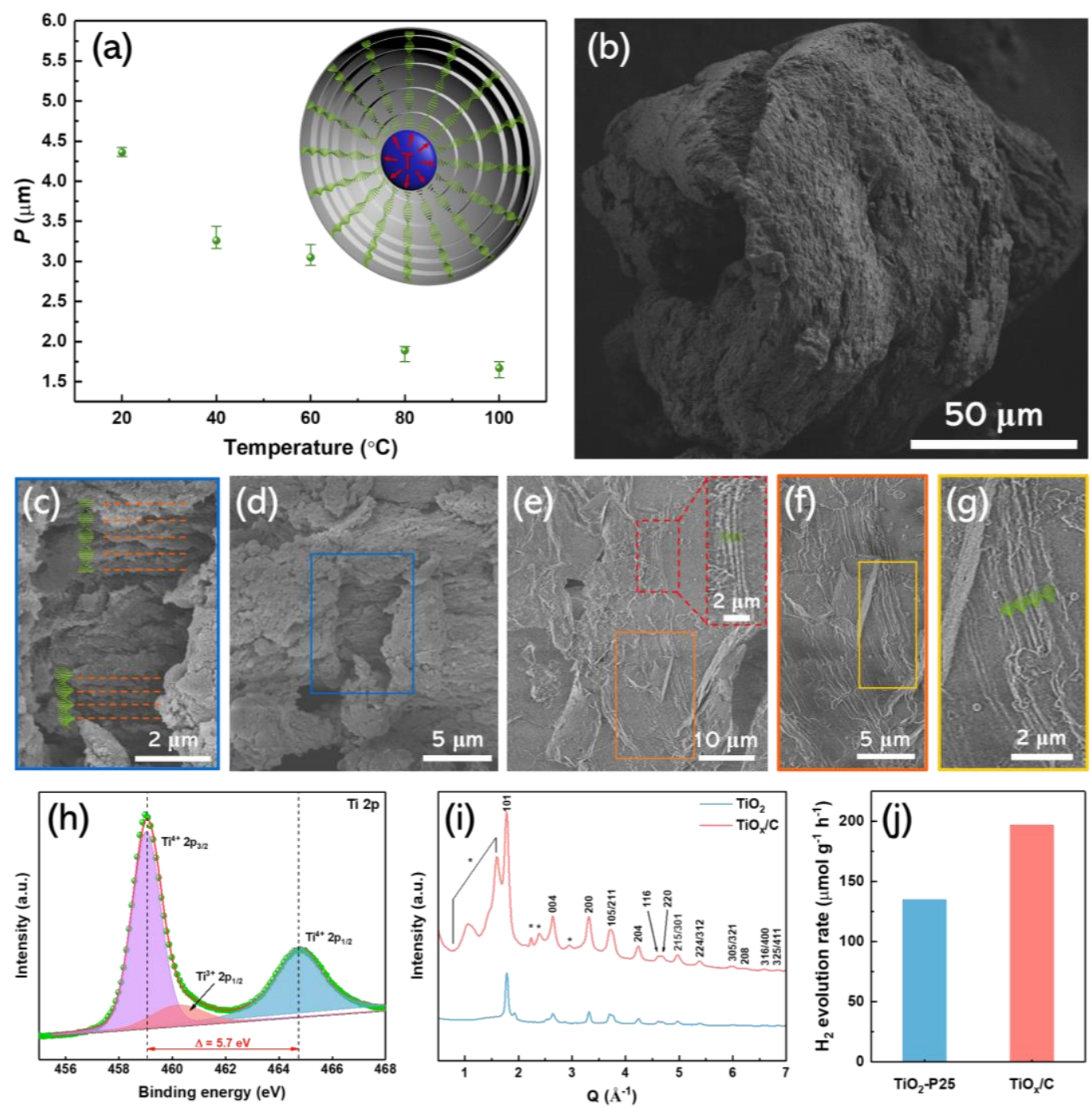

Figure 5. (a) The effect of temperature on $P$. The inset is a 3D schematic diagram of $P$ compressed at higher temperature. (b) SEM image of TiO $/ / \mathrm{C}$ microsphere with wrinkles on the surface and a hole in the centre. (c-g) Cross-section SEM images of microspheres showing $\mathrm{Ch}$ nematic structures with periodic lamellar bands. (h) XPS spectrum of Ti 2p. (i) WAXS patterns of $\mathrm{TiO}_{x} / \mathrm{C}$ microspheres. (j) Hydrogen generation constant rate of $\mathrm{TiO}_{x} / \mathrm{C}$ microspheres and commercial $\mathrm{TiO}_{2}-\mathrm{P} 25$.

\section{CONCLUSION}

In summary, we comprehensively monitored the self-organization process of CNCs in confined titania-sol microdroplet by employing a rapid-term emulsification method. The optimization of concentration allowed to perform a real-time POM observation of the nucleation and growth of tactoids. Tactoids coalescence was the key process that guided the phase transition of mixtures from isotropic to Ch nematic phase. Two coalescence mechanisms of tactoids, "head-to-tail" and "side-to-side", were revealed during the growth process. The phase separation induced by the spherical constraint eventually leads to a microdroplet with $\mathrm{Ch}$ nematic shell and isotropic core. With the assistance of hydrothermal approach, we successfully replicated the $\mathrm{Ch}$ nematic structures into hybrid nanostructured $\mathrm{TiO}_{x} / \mathrm{C}$ microspheres. The present work offers a deeper insight and substantial understanding of the assembly process of bioinspired materials in spherical geometry, and paves a promising way in the design of novel microspheres with unique Ch nematic structures, which could be widely applied in the fields of catalysis, photocatalysis and Mie scattering.

\section{EXPERIMENTAL SECTION}

\subsection{Preparation of TAA/CNC mixtures}

Different volumes of TAA solutions (Table $\mathrm{S} 1$ ) were added in 1 $\mathrm{mL}$ ethanol stirred for $10 \mathrm{~min}$, then mixed with $5 \mathrm{~mL}$ CNCs aqueous suspension $(\mathrm{pH}=6.3)$. Homogeneous transparent yellow mixtures can be obtained after 30 min stirring under room temperature. More details could be found in Ref. 7 .

\subsection{Fabrication of $\mathrm{TAA} / \mathrm{CNC}$ microdroplets and $\mathrm{TiO}_{x} / \mathrm{C}$ microspheres}

Typically, Span $80(0.47 \mathrm{~g})$ was mixed with cyclohexane $(30 \mathrm{~mL})$ and sonicated for $10 \mathrm{~min}$ to obtain a transparent solution, then transferred to a $100 \mathrm{~mL}$ round-bottom flask with magnetic stir bar. The prepared TAA/CNC solution was added dropwise into the flask and maintained a stirring speed at $500 \mathrm{rpm}$. After rapid-term 
emulsification at ambient temperature $\left(20^{\circ} \mathrm{C}\right)$, allowing the original state to be studied under POM. The effect of temperature on the Ch nematic structure was investigated by changing the emulsification temperature (varied from 20 to $100{ }^{\circ} \mathrm{C}$ ). To synthesize the $\mathrm{TiO}_{x} / \mathrm{C}$ microspheres, TAA/CNC $6 \%$ microdroplets were emulsified in a sealed flask at $60{ }^{\circ} \mathrm{C}$ for $90 \mathrm{~min}$, then introduced into a Teflon-lined autoclave $(50 \mathrm{~mL})$ and heated at $180{ }^{\circ} \mathrm{C}$ for $18 \mathrm{~h}$. The black solid microspheres were washed with ethanol and collected by centrifugation, then dried overnight in oven.

\subsection{Characterization}

The structures of suspensions and microdroplets (CNCs and $\mathrm{TAA} / \mathrm{CNC}$ ) were recorded by polarizing optical microscopy (POM) between crossed polarizers on a Zeiss Axio-Observer equipped with a Sony Cyber-shot DSC-W570. The X-ray photoelectron spectroscopies (XPS) of $\mathrm{TiO}_{x} / \mathrm{C}$ microspheres were obtained on an ESCALAB 250 spectrophotometer with Al-Ka radiation, and the binding energies were calibrated using $\mathrm{C} 1 \mathrm{~s}$ at $284.6 \mathrm{eV}$. The thermogravimetric analysis (TGA) was performed by a thermal analyer (TGA-Q500) with a heating rate of $10^{\circ} \mathrm{C} / \mathrm{min}$ from 25 to $800^{\circ} \mathrm{C}$ in air. Wide-angle X-ray scattering (WAXS) measurements were performed on a molybdenum rotating anode generator ( $\lambda$ MoKa $=0.711 \AA$, Rigaku Corp., Japan) equipped with a multilayer W/Si mirror (Osmic) providing a monochromatic beam of $1 \times 1 \mathrm{~mm}^{2}$ at the sample position. Two-dimensional WAXS patterns were collected on a MAR345 detector (marXperts $\mathrm{GmbH}$ Germany) with $150 \mu \mathrm{m}$ pixel size, placed at a sample-to-detector distance of $150 \mathrm{~mm}$. The typical accessible range of scattering vector modulus $Q$ was $0.4-7 \AA^{-1}(Q=4 \pi / \lambda \sin (\theta)$, where $\lambda$ is the incident wavelength and $2 \theta$ is the scattering angle). The scanning electron microscopy (SEM) image was acquired with a ZEISS Supra 55VP FEG-SEM with an operating voltage of $2 \mathrm{kV}$ and a working distance of 3 to $5.7 \mathrm{~mm}$. Diffusion reflectance spectras (DRS) were recorded in the range of $200-800 \mathrm{~nm}$ using a UVvisible Agilent Cary-5000 spectrophotometer. The baseline was recorded using $\mathrm{BaSO}_{4}$ as a reference.

\subsection{Photocatalytic $\mathrm{H}_{2}$ evolution test}

The photocatalytic $\mathrm{H}_{2}$ evolution experiments were carried out in a $10 \mathrm{~mL}$ quartz reactor under UV light irradiation. Firstly, $4 \mathrm{mg}$ $\mathrm{TiO}_{\mathrm{x}} / \mathrm{C}$ was dispersed in $4 \mathrm{~mL}$ aqueous solution containing $0.5 \mathrm{M}$ $\mathrm{Na}_{2} \mathrm{~S}$ and $0.5 \mathrm{M} \mathrm{Na}_{2} \mathrm{SO}_{3}$. Then, the reactor was degassed with $\mathrm{Ar}$ for 20 mins to remove dissolved oxygen and ensure an anaerobic condition. Oriel $300 \mathrm{~W}$ Xenon lamp with an infrared water filter was employed to irradiate the samples for 4 hours under stirring. In comparison with our hybrid nanocomposite, $4 \mathrm{mg}$ commercial $\mathrm{TiO}_{2}-\mathrm{P} 25$ was used as the reference. The generated gas from the reactor was analyzed by gas chromatography (Micro GC Fusion).

\section{ASSOCIATED CONTENT}

\section{Supporting Information}

The Supporting Information is available free of charge at https://XXX

Molecular structures, POM images, schematic 3D model, scanning electronic microscopy, thermogravimetric analysis, UVvisible spectra, XPS, $\mathrm{H}_{2}$ evolution vs time, POM videos

\section{Author Contributions}

C.W. performed the experiments and curated the data. E.P. carried out the polarized optical microscopy experiments. H.R. discussed the results. M.N.G. conceived and supervised the work. The manuscript was written through contributions of all authors.

\section{Note}

The authors declare no competing interests.

\section{ACKNOWLEDGMENTS}

Cong Wang acknowledges the China Scholarship Council (CSC) for his fellow research position. We thank François Brisset for his help in performing the SEM images and Diana Dragoe for the XPS analysis. The work was supported by the French National Research Agency (ANR) under the framework of INGENCAT's project, convention ANR-20-CE43-0014-03.

\section{REFERENCES}

1. Vanderfleet, O. M.; Cranston, E. D., Production routes to tailor the performance of cellulose nanocrystals. Nat. Rev. Mater. 2020, 121.

2. Kose, O.; Tran, A.; Lewis, L.; Hamad, W. Y.; MacLachlan, M. J., Unwinding a spiral of cellulose nanocrystals for stimuli-responsive stretchable optics. Nat. Commun. 2019, 10, (1), 1-7.

3. Giese, M.; Blusch, L. K.; Khan, M. K.; MacLachlan, M. J., Functional materials from cellulose-derived liquid-crystal templates. Angew. Chem. Int. Ed. Engl. 2015, 54, (10), 2888-910.

4. Tran, A.; Boott, C. E.; MacLachlan, M. J., Understanding the Self-Assembly of Cellulose Nanocrystals-Toward Chiral Photonic Materials. Adv. Mater. 2020, e1905876.

5. Wilts, B. D.; Whitney, H. M.; Glover, B. J.; Steiner, U.; Vignolini, S., Natural Helicoidal Structures: Morphology, Self-assembly and Optical Properties. Materials Today: Proceedings 2014, 1, 177-185.

6. Wang, L.; Urbas, A. M.; Li, Q., Nature-Inspired Emerging Chiral Liquid Crystal Nanostructures: From Molecular Self-Assembly to DNA Mesophase and Nanocolloids. Adv. Mater. 2020, 32, (41), e1801335.

7. Wang, C.; Li, J.; Paineau, E.; Laachachi, A.; Colbeau-Justin, C.; Remita, H.; Ghazzal, M. N., A sol-gel biotemplating route with cellulose nanocrystals to design a photocatalyst for improving hydrogen generation. J. Mater. Chem. A 2020, 8, (21), 10779-10786.

8. Nguyen, T.-D.; Lizundia, E.; Niederberger, M.; Hamad, W. Y.; MacLachlan, M. J., Self-Assembly Route to TiO2 and TiC with a Liquid Crystalline Order. Chem. Mater. 2019, 31, (6), 2174-2181.

9. Xiong, R.; Luan, J.; Kang, S.; Ye, C.; Singamaneni, S.; Tsukruk, V. V., Biopolymeric photonic structures: design, fabrication, and emerging applications. Chem. Soc. Rev. 2020, 49, (3), 983-1031.

10. Liu, Y.; Agthe, M.; Salajkova, M.; Gordeyeva, K.; Guccini, V.; Fall, A.; Salazar-Alvarez, G.; Schutz, C.; Bergstrom, L., Assembly of cellulose nanocrystals in a levitating drop probed by time-resolved small angle X-ray scattering. Nanoscale 2018, 10, (38), 18113-18118.

11. Hiratani, T.; Hamad, W. Y.; MacLachlan, M. J., Transparent Depolarizing Organic and Inorganic Films for Optics and Sensors. Adv. Mater. 2017, 29, (13).

12. Tardy, B. L.; Ago, M.; Guo, J.; Borghei, M.; Kamarainen, T.; Rojas, O. J., Optical Properties of Self-Assembled Cellulose Nanocrystals Films Suspended at Planar-Symmetrical Interfaces. Small 2017, 13, (47).

13. Shopsowitz, K. E.; Qi, H.; Hamad, W. Y.; Maclachlan, M. J., Free-standing mesoporous silica films with tunable chiral nematic structures. Nature 2010, 468, (7322), 422-5.

14. Shopsowitz, K. E.; Kelly, J. A.; Hamad, W. Y.; MacLachlan, M. J., Biopolymer Templated Glass with a Twist: Controlling the Chirality, Porosity, and Photonic Properties of Silica with Cellulose Nanocrystals. Adv. Funct. Mater. 2014, 24, (3), 327-338.

15. Zhao, T. H.; Parker, R. M.; Williams, C. A.; Lim, K. T. P.; Frka Petesic, B.; Vignolini, S., Printing of Responsive Photonic Cellulose 
Nanocrystal Microfilm Arrays. Adv. Funct. Mater. 2018, 29, (21), 1804531.

16. Wang, P. X.; MacLachlan, M. J., Liquid crystalline tactoids: ordered structure, defective coalescence and evolution in confined geometries. Philos Trans A Math Phys Eng Sci 2018, 376, (2112).

17. Park, J. H.; Noh, J.; Schütz, C.; Salazar-Alvarez, G.; Scalia, G.; Bergström, L.; Lagerwall, J., Macroscopic control of helix orientation in films dried from cholesteric liquid crystalline cellulose nanocrystal suspensions. Chemphyschem: a European journal of chemical physics and physical chemistry 2014, 15, (7), 1477-1484.

18. Wang, P. X.; Hamad, W. Y.; MacLachlan, M. J., Structure and transformation of tactoids in cellulose nanocrystal suspensions. Nat Commun. 2016, 7, 11515.

19. Wang, L.; Chen, D.; Gutierrez-Cuevas, K. G.; Bisoyi, H. K.; Fan, J.; Zola, R. S.; Li, G.; Urbas, A. M.; Bunning, T. J.; Weitz, D. A.; Li, Q., Optically Reconfigurable Chiral Microspheres of Self-Organized Helical Superstructures with Handedness Inversion. Mater Horiz 2017 4, (6), 1190-1195.

20. Lee, S. S.; Kim, B.; Kim, S. K.; Won, J. C.; Kim, Y. H.; Kim, S. $\mathrm{H}$., Robust microfluidic encapsulation of cholesteric liquid crystals toward photonic ink capsules. Adv. Mater. 2015, 27, (4), 627-33.

21. Song, D. P.; Zhao, T. H.; Guidetti, G.; Vignolini, S.; Parker, R. M., Hierarchical Photonic Pigments via the Confined Self-Assembly of Bottlebrush Block Copolymers. ACS Nano 2019, 13, (2), 1764-1771. 22. Lee, S. S.; Seo, H. J.; Kim, Y. H.; Kim, S. H., Structural Color Palettes of Core-Shell Photonic Ink Capsules Containing Cholesteric Liquid Crystals. Adv. Mater. 2017, 29, (23).

23. Park, S.; Lee, S. S.; Kim, S. H., Photonic Multishells Composed of Cholesteric Liquid Crystals Designed by Controlled Phase Separation in Emulsion Drops. Adv. Mater. 2020, 32, (30), e2002166. 24. Noh, J.; Liang, H.-L.; Drevensek-Olenik, I.; Lagerwall, J. P. F., Tuneable multicoloured patterns from photonic cross-communication between cholesteric liquid crystal droplets. J. Mater. Chem. C 2014 2, (5), 806-810.

25. Wang, P. X.; Hamad, W. Y.; MacLachlan, M. J., Polymer and Mesoporous Silica Microspheres with Chiral Nematic Order from Cellulose Nanocrystals. Angew. Chem. Int. Ed. Engl. 2016, 128, (40), 12648-12652.

26. Parker, R. M.; Frka-Petesic, B.; Guidetti, G.; Kamita, G. Consani, G.; Abell, C.; Vignolini, S., Hierarchical Self-Assembly of Cellulose Nanocrystals in a Confined Geometry. ACS Nano 2016, 10 , (9), 8443-9.

27. Li, Y.; Jun-Yan Suen, J.; Prince, E.; Larin, E. M.; Klinkova, A.; Therien-Aubin, H.; Zhu, S.; Yang, B.; Helmy, A. S.; Lavrentovich, O. D.; Kumacheva, E., Colloidal cholesteric liquid crystal in spherical confinement. Nat. Commun. 2016, 7, 12520.

28. Li, Y.; Nancy Khuu; Elisabeth Prince; Moien Alizadehgiashi; Elizabeth Galati; Oleg D. Lavrentovich; Kumacheva, E., Nanoparticleladen droplets of liquid crystals: Interactive morphogenesis and dynamic assembly. Sci. Adv. 2019, 5, 1-9.

29. Li, Y.; Prince, E.; Cho, S.; Salari, A.; Mosaddeghian Golestani, Y.; Lavrentovich, O. D.; Kumacheva, E., Periodic assembly of nanoparticle arrays in disclinations of cholesteric liquid crystals. Proc. Nat. Acad. Sci. 2017, 114, (9), 2137-2142.

30. Araki, J.; Kuga, S., Effect of Trace Electrolyte on Liquid Crystal Type of Cellulose Microcrystals. Langmuir 2001, 17, 4493-4496.

31. Dong, X. M.; Kimura, T.; Revol, J.-F.; Gray, D. G., Effects of Ionic Strength on the Isotropic-Chiral Nematic Phase Transition of Suspensions of Cellulose Crystallites. Langmuir 1996, 12, 2076-2082. 32. Li, C.; Julian Evans; Nan Wang; Tingbiao Guo; He, S., pH dependence of the chirality of nematic cellulose nanocrystals. Sci. Rep. 2019, 9, 1-7.

33. Bejoy Thomas; Midhun C. Raj; Athira K. B; Rubiyah M. H; Jithin Joy; Audrey Moores; Glenna L. Drisko; Sanchez, C., Nanocellulose, a Versatile Green Platform: From Biosources to Materials and Their Applications. Chem. Rev. 2018, 118, (24), 11575-11625.

34. Tran, A.; Hamad, W. Y.; MacLachlan, M. J., Tactoid Annealing Improves Order in Self-Assembled Cellulose Nanocrystal Films with Chiral Nematic Structures. Langmuir 2018, 34, (2), 646-652.

35. Parker, R. M.; Guidetti, G.; Williams, C. A.; Zhao, T.; Narkevicius, A.; Vignolini, S.; Frka-Petesic, B., The Self-Assembly of Cellulose Nanocrystals: Hierarchical Design of Visual Appearance. Adv. Mater. 2018, 30, (19), e1704477.

36. Frka-Petesic, B.; Kelly, J. A.; Jacucci, G.; Guidetti, G.; Kamita G.; Crossette, N. P.; Hamad, W. Y.; MacLachlan, M. J.; Vignolini, S.,
Retrieving the Coassembly Pathway of Composite Cellulose Nanocrystal Photonic Films from their Angular Optical Response. Adv. Mater. 2020, 32, (19), e1906889.

37. Schutz, C.; Agthe, M.; Fall, A. B.; Gordeyeva, K.; Guccini, V.; Salajkova, M.; Plivelic, T. S.; Lagerwall, J. P.; Salazar-Alvarez, G. Bergstrom, L., Rod Packing in Chiral Nematic Cellulose Nanocrystal Dispersions Studied by Small-Angle X-ray Scattering and Laser Diffraction. Langmuir 2015, 31, (23), 6507-13.

38. Aline F. Miller; Donald, A. M., Imaging of Anisotropic Cellulose Suspensions Using Environmental Scanning Electron Microscopy. Biomacromolecules 2003, 4, 510-517.

39. Abitbol, T.; Kam, D.; Levi-Kalisman, Y.; Gray, D. G.; Shoseyov, O., Surface Charge Influence on the Phase Separation and Viscosity of Cellulose Nanocrystals. Langmuir 2018, 34, (13), 3925-3933.

40. Grelet, E.; Fraden, S., What is the origin of chirality in the cholesteric phase of virus suspensions? Phys. Rev. Lett. 2003, 90, (19), 198302.

41. Straley, J. P., Theory of piezoelectricity in nematic liquid crystals, and of the cholesteric ordering. Phys. Rev. A 1976, 14, (5), 1835.

42. Lagerwall, J. P. F.; Schütz, C.; Salajkova, M.; Noh, J.; Hyun Park, J.; Scalia, G.; Bergström, L., Cellulose nanocrystal-based materials: from liquid crystal self-assembly and glass formation to multifunctional thin films. NPG Asia Materials 2014, 6, (1), e80-e80.

43. Yarovoy, Y.; Labes, M., Effect of chiral polymers on lyotropic liquid crystals. J. Am. Chem. Soc. 1997, 119, (50), 12109-12113.

44. Wensink, H. H.; Jackson, G., Cholesteric order in systems of helical Yukawa rods. J Phys Condens Matter 2011, 23, (19), 194107. 45. Onsager, L., The effects of shape on the interaction of colloidal particles. Ann. N. Y. Acad. Sci. 1949, 51, (4), 627-659.

46. Chen, W.; Gray, D. G., Interfacial tension between isotropic and anisotropic phases of a suspension of rodlike particles. Langmuir 2002, 18, (3), 633-637.

47. O'Keeffe, O.; Wang, P. X.; Hamad, W. Y.; MacLachlan, M. J., Boundary Geometry Effects on the Coalescence of Liquid Crystalline Tactoids and Formation of Topological Defects. J Phys Chem Lett 2019, 10, (2), 278-282.

48. Xu, Y.-T.; Wang, P.-X.; MacLachlan, M. J., Self-Assembly of Two-Dimensional Colloids in Spherical Space. J. Phys. Chem. C 2019, 123, (27), 17049-17055.

49. Verhoeff, A. A.; Bakelaar, I. A.; Otten, R. H.; van der Schoot, P.; Lekkerkerker, H. N., Tactoids of plate-like particles: size, shape, and director field. Langmuir 2011, 27, (1), 116-25.

50. Aletta A. Verhoeff; Ronald H. J. Otten; Paul van der Schoot; Lekkerkerker, H. N. W., Shape and Director Field Deformation of Tactoids of Plate-Like Colloids in a Magnetic Field. J. Phys. Chem. B 2009, 113, 3704-3708.

51. Khadem, S. A.; Bagnani, M.; Mezzenga, R.; Rey, A. D., Relaxation dynamics in bio-colloidal cholesteric liquid crystals confined to cylindrical geometry. Nat. Commun. 2020, 11, (1), 4616. 52. Cerda, E.; Mahadevan, L., Geometry and physics of wrinkling Phys. Rev. Lett. 2003, 90, (7), 074302.

53. Ghazzal, M. N.; Kebaili, H.; Joseph, M.; Debecker, D. P.; Eloy, P.; De Coninck, J.; Gaigneaux, E. M., Photocatalytic degradation of Rhodamine $6 G$ on mesoporous titania films: Combined effect of texture and dye aggregation forms. Appl. Catal. B 2012, 115-116, 276-284.

54. Bharti, B.; Kumar, S.; Lee, H. N.; Kumar, R., Formation of oxygen vacancies and $\mathrm{Ti}\left(3_{+}\right)$state in $\mathrm{TiO} 2$ thin film and enhanced optical properties by air plasma treatment. Sci Rep 2016, 6, 32355.

55. Gesesse, G. D.; Li, C.; Paineau, E.; Habibi, Y.; Remita, H.; Colbeau-Justin, C.; Ghazzal, M. N., Enhanced Photogenerated Charge Carriers and Photocatalytic Activity of Biotemplated Mesoporous TiO2 Films with a Chiral Nematic Structure. Chem. Mater. 2019, 31, (13), 4851-4863. 


\section{Entry for the Table of Contents}

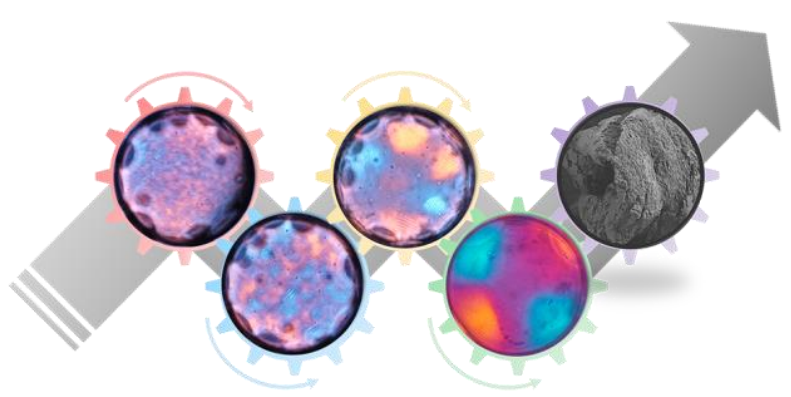

The self-organization process of cellulose nanocrystals in spherical titania-sol microdroplets is comprehensively monitored through polarized optical microscopy. Tactoids coalescence is the key process that guided the phase transition of suspensions from isotropic to chiral nematic. A successful transfer of the chiral nematic structure into hybrid $\mathrm{TiO}_{x} / \mathrm{C}$ microspheres demonstrates its great potential in photocatalytic hydrogen generation. 